\title{
The variation of optical absorption edge with sintering time for the ceramic $\mathrm{ZnO}+$ xMnO2-Bi2O3-TiO2
}

\begin{abstract}
Photopyroelectric spectroscopy is used to study the variation of optical absorption of the ceramic xMn02 - $0.4 \mathrm{Bi} 2 \mathrm{O} 3-0.4 \mathrm{TiO} 2-\mathrm{ZnO}, \mathrm{x}=0,0.4 \mathrm{~mol} \%$ sintered for $1-4$ hours at the isothermal temperature, $1220^{\circ} \mathrm{C}$. The wavelength of incident light, modulated at $12 \mathrm{~Hz}$, is kept in the range 310 to $810 \mathrm{~nm}$. The band-gap energy is reduced from $3.2 \mathrm{eV}$ (for pure $\mathrm{ZnO}$ ) to $2.83 \mathrm{eV}$ for $0 \mathrm{~mol} \% \mathrm{MnO} 2$ for 1 hour sintering time and decreases further with the further increase of sintering time. Eg is decreased to $2.39 \mathrm{eV}$ for 1 hour sintering time after the addition of $0.4 \mathrm{~mol} \%$ of $\mathrm{MnO} 2$ in the ceramic combination. It is reduced to a value $1.9 \mathrm{eV}$ with the further increase of sintering time. The variation of steepness factor $\mathrm{U} A$ and $\mathrm{B} B$ which characterizes the slop of exponential optical absorption, is correlated with the variation of Eg, sintering time and doping of $\mathrm{MnO} 2$. Microstructure and compositional analysis of the selected areas are analyzed using SEM and EDAX.
\end{abstract}

